\title{
An Exploration of the Combined Impact of Ethical Climate and Work Locus of Control on Job Performance and Turnover Intentions: An Abstract
}

\author{
Jay Prakash Mulki and Felicia G. Lassk
}

\begin{abstract}
Researchers prescribe that the combined influence of personal characteristics and work conditions should be examined to provide a clearer understanding of performance at work. Here we explore the combined impact of ethical climate and salespeople's external WLOC on job meaningfulness. This study suggests that when salespeople perceive that their sales organization has a strong ethical climate, the negative impact of external WLOC is mitigated on key predictors of sales performance and turnover intentions. The following hypotheses were tested with a sample of 143 B2B salespeople from a sales organization based in the Southeastern USA:

$H_{1}$ : External WLOC is negatively related to job meaningfulness.

$\mathrm{H}_{2}$ : Ethical climate is positively related to job meaningfulness.

$\mathrm{H}_{3}$ : Job meaningfulness is positively related to job performance.

$H_{4}$ : Job meaningfulness is negatively related to turnover intentions.

$\mathrm{H}_{5}$ : Job performance is negatively related to turnover intentions.

$H_{6}$ : Ethical climate moderates the impact of external WLOC on job meaningfulness.

Results show an acceptable fit with the data and supported all hypotheses except for $\mathrm{H}_{5}$. The moderating hypothesis showed that ethical climate dampened the negative relationship between external WLOC and job meaningfulness. The study results contribute to the knowledge about ethical climate and external WLOC in important ways showing a negative relationship to job meaningfulness. The beneficial role played by firm's ethical climate in shaping salesperson's attitudes and behaviors is another contribution. The study highlights the need for sales managers to be aware of the potential negative impact of external WLOC during hiring and utilize the competitive advantage facilitated by firm's ethical climate during training programs.
\end{abstract}

References Available Upon Request

J. P. Mulki · F. G. Lassk ( $\bowtie)$

Northeastern University, Boston, MA, USA

e-mail: j.mulki@northeastern.edu; f.lassk@ northeastern.edu

(C) Academy of Marketing Science 2019 